\title{
Numerical Analysis of Laser Preheating for Laser Assisted Micro Milling of Inconel 718
}

\author{
E. A. Rahim ${ }^{1, a}$, N. M. Warap ${ }^{1, b}$, Z. Mohid ${ }^{1, c}$, R. Ibrahim $^{1}$ and N. Rafai ${ }^{1}$ \\ ${ }^{1}$ Advanced Machining Research Group, Faculty of Mechanical and Manufacturing Engineering, \\ UniversitiTun Hussein Onn Malaysia, 86400, Parit Raja, BatuPahat, Johor, Malaysia. \\ aerween@uthm.edu.my, bpondox84@yahoo.com, 'zazuli@uthm.edu.my
}

Keywords: Laser Assisted Micro Milling, Finite Element Analysis, Nd:YAG Laser.

\begin{abstract}
Micro milling of super alloy materials such as Inconel 718 is challenging due to their excellent mechanical properties. Therefore, new techniques have been suggested to enhance the machinability such as pre-heating the workpiece's surface to reduce their strength and ductility. Applying pulsed wave laser as a heat source, the prediction of fluctuated temperature distribution in laser assisted micro milling (LAMM) is crucially important. The selection of processing parameters with minimum effect on the processing characteristic is decisive in obtaining high machining quality. Clarifying the effect of heat generated underneath the laser irradiated surface is important to predict the allowable maximum cutting depth and to minimize the risk of tool wear and failure. In this study, ANSYS APDL numerical analysis was used to characterise the workpiece temperature distribution. The numerical model was validated by comparing the results with actual laser irradiation experiment. The experiment was conducted by using Nd:YAG laser with wavelength $1064 \mathrm{~nm}$.
\end{abstract}

\section{Introduction}

Laser technology is applied in various applications such as cutting, welding, drilling, cladding and pre-heating process. In laser assisted machining (LAM), laser is used to pre-heat the workpiece material before milling process to reduce the material strength. However, it is important to control the preheating temperature in order to avoid significant mechanical properties and microstructure changes on the laser irradiated area.

Prediction of heat generation and distribution initiated by laser irradiation using finite element analysis (FEA) software has been widely reported by many researchers. Saodari and Majumdar [1] used FEA to analyze the heating rate, heat affected zone and the shape and size of the molten pool using Gaussian laser beam. In addition, they also analyzed the effect of mesh size to obtain accurate prediction result. Mohid et al. [2] reported the effect of absorptivity, $A$ and Gaussian distribution constant, $K$ value on the accuracy of the numerical analysis results. The investigation shows that the $A$ and $K$ values have a significant effect on the characterization of melting pool and heat effected zone (HAZ) pattern. Furthermore, Ren et al. [3] was using FEA to analyses the effect of heat generated on residual stress during laser processing.

In LAM, the determination of melting pool and HAZ region created by laser irradiation is crucially important. It is needed to confirm that the selection of laser beam-to-cutting tool distance $\left(X_{t-b}\right)$ and depth of cut $\left(t_{c}\right)$ is able to reduce the cutting force and tool wear subsequently increase the machining performance. Mohid et al. [4] have predicted the temperature distribution on pulsed laser mode by using ANSYS APDL software. From the result, it was concluded that by using average laser power $\left(P_{\text {avg }}\right)$ of $140 \mathrm{~W}, X_{t-b}$ can be set between 0.8 and $1.9 \mathrm{~mm}$. In addition, the recommended $t_{c}$ is between 0.005 and $0.117 \mathrm{~mm}$ respectively. Yang et al. [5] have developed 3D transient finite element method to predict the depth and width of HAZ on ductile material. It was found that the laser parameter especially laser power has strongly influenced the depth and width of HAZ. In addition, Kim and Lee [6] used FEA to predict the pre-heating temperature of Inconel 718 and AISI 1045 material to obtain the value of $t_{c}$. 
Thus, it is important to determine the applicable $t_{c}$ and $X_{t-b}$ that could give minimum effect on cutting tool and workpiece properties changes. In this study, the FEA model was developed by using ANSYS APDL software to predict the heat distribution during laser irradiation and HAZ pattern could be created by the laser heating process. Based on workpiece temperature distribution, the range of $X_{t-b}$ and $t_{c}$ can be determined prior the actual machining process. Finally, the results of cutting force and surface roughness were compared between conventional and LAMM to evaluate the effectiveness of laser preheating. The micro milling experiments were carried out by considering the effective cutting tool diameter in $10^{\circ}$ tool inclination and the performance of coating in the machining of Inconel 718 nickel alloy.

\section{Methodology}

Finite Element Model. In this study, a finite element model with the inclination of laser beam of $55^{\circ}$ as the heat source was developed to represent the actual laser irradiation experiment. The model was drawn with width, length and thickness of $2 \mathrm{~mm}, 4 \mathrm{~mm}$ and $1 \mathrm{~mm}$ respectively. It was developed in half of the total width to reduce the total number of element and computational processing time. Fig. 1 (a) shows the half three-dimensional finite element model generated using ANSYS Parametric Design Language (APDL) software. The total number of element was 70503. To secure the simulation result accuracy, the elements in the centre of the model (L1) (scanning path) was drew with the finest element size compared to the other areas (L2 to L7). Elements with triangle shape were used to connect the finest elements to the bigger elements. The program is automatically time stepping with consider the different between two point and it also depending on the pulsed length was applied as shown in Fig. 1 (b).

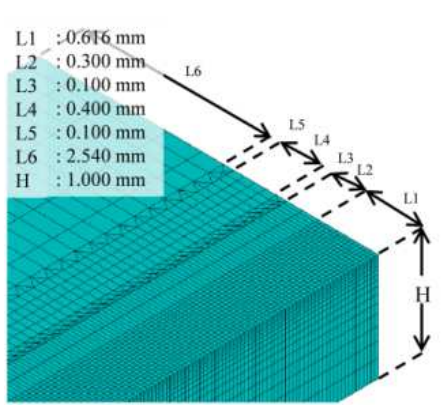

(a)

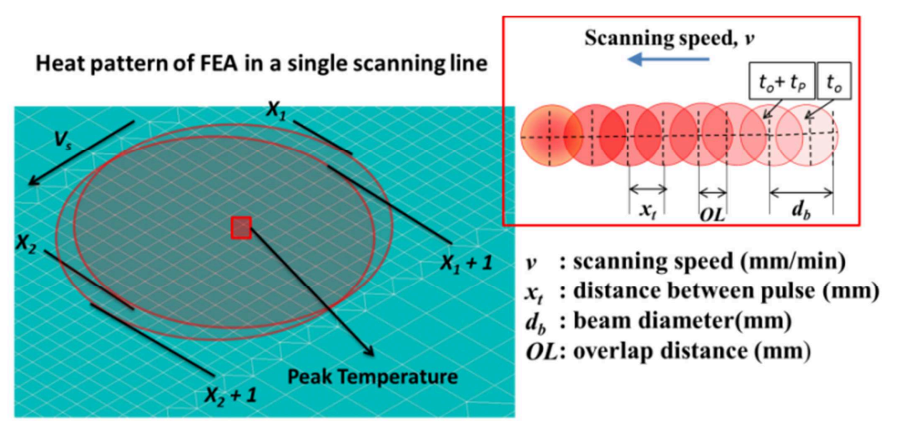

(b)

Fig. 1: Mesh and element distribution for FEM model

Validations. The model can be assumed precise when the depth and width of the melting pool in the numerical simulation are comparable with actual experiment. In this case, the error of less than $10 \%$ in melting and HAZ geometry is considered acceptable to validate the model as shown in Fig. 2. The recorded melting temperature in the simulation was ranging from 1250 to $1533 \mathrm{~K}$. It represents the boundary line of melting point. The HAZ boundary lines were defined by face transformation temperature from $\gamma^{\prime}$ to $\gamma^{\prime \prime}$, which is $800 \mathrm{~K}$. An optical microscope was used to measure the size of melted zone (MZ) and HAZ.

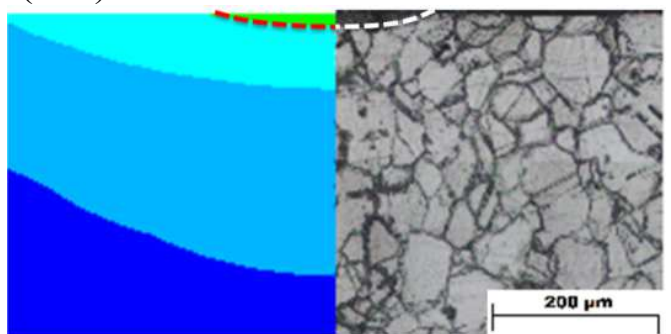

Fig. 2: Comparison of MZ and HAZ size $\left(P_{a v g}=5.65 \mathrm{~W}, A=35 \%\right.$ and $\left.K=2.5\right)$ 
Laser Assisted Micro Milling. Two flutes AlTiN coated carbide ball mill with the maximum tip diameter of $300 \mu \mathrm{m}$ were used to create linear groove on the workpiece. An Inconel 718 (21-23 HRC) with the thickness of approximately $6 \mathrm{~mm}$ has been chosen as the workpiece material. The cutting tools were mounted to the air bearing spindle with maximum rotational speed, $(N)$ of 60,000 rpm (Fig. 3). In this study, the machining process were performed using variable cutting speed, $v_{c}$, and spindle speed, $N$, and at the constant feed rate, $f_{r}$ of $70 \mathrm{~mm} / \mathrm{min}$. In the case of LAMM, $X_{t-b}$ was fixed at $600 \mu \mathrm{m}$ in order to avoid the laser beam irradiate into the cutting tool at constant power, $P_{\text {avg }}$ of $4.16 \mathrm{~W}$.

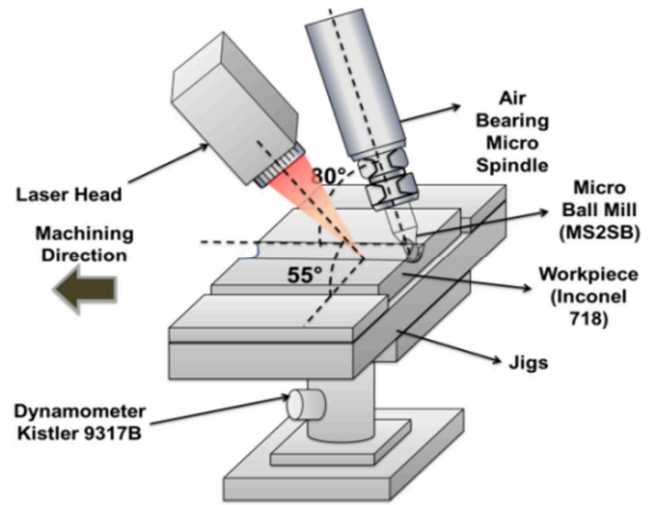

Fig. 3: Machining setup for laser assisted micro milling process

\section{Result and Discussion}

Numarical Anlysis. $X_{t-b}$ is determined by referring to the temperature generated at the centre of irradiation line in FEA. Pre-heating process by pulsed wave laser creates massive temperature fluctuation value as shown in Fig. 4 (a). Cooling time between pulsed was sufficient for specimen to chill down. Therefore, equation (1) can be used to determine the value of $X_{t-b}(\mu \mathrm{m})$. Cooling period from peak temperature to deformation temperature of Inconel 718 was recorded as a time different, $T_{d}$ (min). Total cooling time taken must be multiplied by the scanning speed, $f_{r}$ to obtain the laser spot-to-cutting tool distance.

$$
\text { Laser - to - tool Diastance, } X_{t-b}=T_{d}\left(f_{r}\right)
$$

Based on calculation, when the $P_{a v g}, t_{p}$ and $A$ is $4.16 \mathrm{~W}, 1 \mathrm{~ms}$, and $35 \%$ respectively, the $X_{t-b}$ was determined to approximately $240 \mu \mathrm{m}$. Meanwhile, the value of $X_{t-b}$ increases as the $P_{\text {avg }}$ is increased due to the increment of preheating temperature generated during the laser irradiation process.

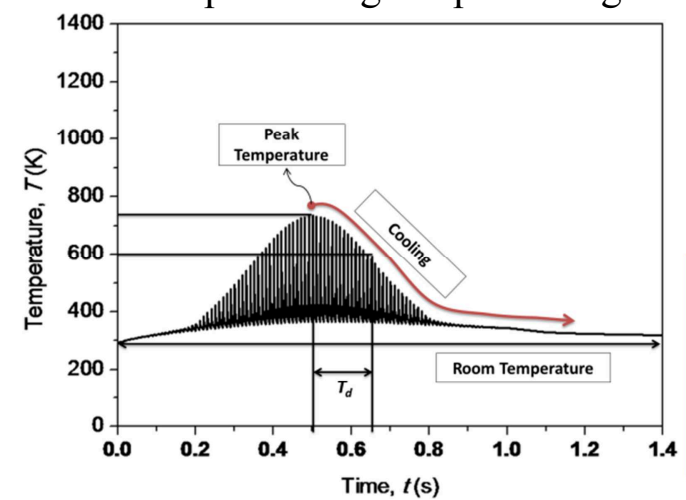

(a)

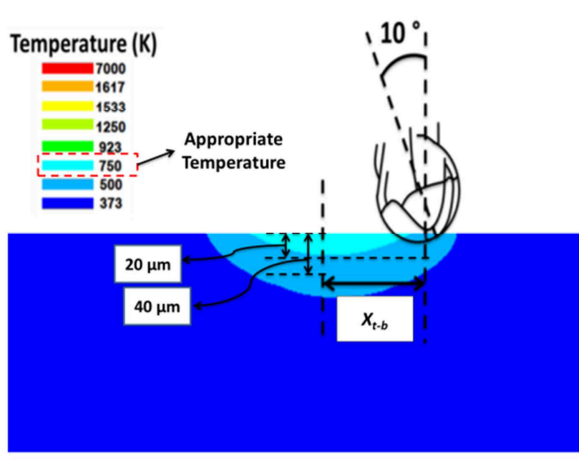

(b)

Fig. 4: Result of temperature distribution when $P_{a v g}=4.16 \mathrm{~W}, t_{p}=1 \mathrm{~ms}$ and $f_{r}=70 \mathrm{~mm} / \mathrm{min}$, (a) recorded temperature at the centre irradiation line (b) Prediction of tool location and the depth of cut when using $P_{\text {avg }}=4.16 \mathrm{~W}, t_{p}=1 \mathrm{~ms}, f_{r}=70 \mathrm{~mm} / \mathrm{min}, A=32 \%$

It is essential to determine the initial tool engagement temperature as shown in Fig. 4 (b). It is intended to ensure that the pre-heating temperature will not impair the tool performance. This 
argument is supported by Kim and Lee [6], reveals that by applying temperature between 650 to $900{ }^{\circ} \mathrm{C}$, the material strength significantly reduce. However, Rahim et al. [7] mentioned that the most prominence effect on cutting force, surface texture and tool wear was defined by laser spot-tocutting tool distance. From the findings, they concluded that it is necessary to control the irradiation temperature. However, in this study the $X_{t-b}$ was fixed at $600 \mu \mathrm{m}$ in order to avoid the the laser beam irradiate into the cutting tool. The workpiece temperature obtained from their study was approximately $400 \mathrm{~K}$.

Surface Texture. Ductile texture was observed as the spindle speed, $N$ cutting speed, $v_{c}$ and depth of cut, $t_{c}$ were increased. Fig. 5 (a) compares the grooves produced by conventional and LAMM process. In all cases, the cutting and spindle speed gives prominent effect on the formation of undeformed chip thickness. The thickness of undeformed chip increases in the down cutting process (from the centre to the left side of the groove) and decreases in the up cutting process (from right side to centre groove). Ono and Matsumura [8] stated that the undeformed chip thicknesses are formed in ductile cutting condition due to a large undeformed chip thickness induced by dynamic displacement of the cutter. In addition, at the bottom of the groove, rubbing phenomenon was observed and the width of feed marks increase significantly when the cutting and spindle speed is increased.

Overall, LAMM shows a significant improvement in the surface texture and the formation of undeformed chip thickness. In the case of $t_{c} 20 \mu \mathrm{m}$, LAMM exhibited an improvement of undeformed chip thickness compared to conventional cutting. Meanwhile, when the $t_{c}$ was increased to $40 \mu \mathrm{m}$, no significant changes was observed in both LAMM and conventional conditions. This phenomenon is due to the temperature effect of the laser pre-heating does not reach at a depth of $40 \mu \mathrm{m}$ to reduce the material strength. Fig. 4 (b) also shows the effective $t_{c}$ when using $P_{a v g}$ of $4.16 \mathrm{~W}$ is approximately $20 \mu \mathrm{m}$. In order to produce batter surface texture in higher $t_{c}$, the $P_{\text {avg }}$ must be increased. However, the preheating temperature must be controlled effectively to avoid large microstructure changes and give inverse effect to cutting tool performance.

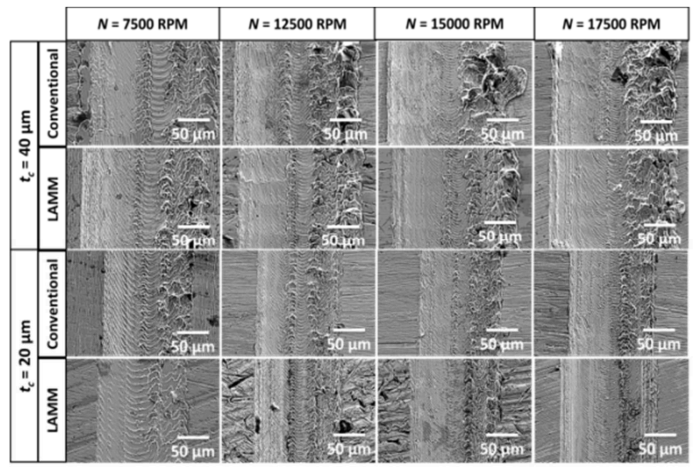

(a)

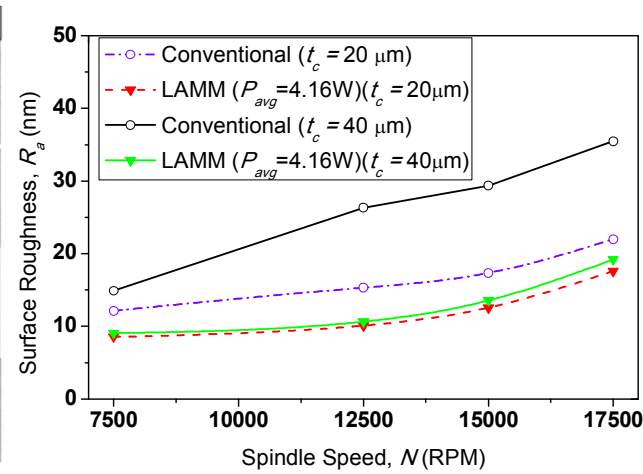

(b)

Fig. 5 : (a) SEM image of groove after cutting process with 500X magnification (b) comparison of surface roughness between LAMM and conventional cutting process.

The formation of feed marks was so obvious when the cutting and spindle speed increase. This is proven by the surface roughness value measured by using atomic force microscopy (AFM). The data was recoded and plotted in Fig. 5 (b). Good agreement was found under LAMM where it produces a fine surface finish compares to the conventional cutting. The combination of an effective $X_{t-b}$ and lower $P_{a v g}$ has provided an appropriate preheating temperature thus reduced the yield strength especially at the $t_{c}$ of $20 \mu \mathrm{m}$. The changes will consequently produce finer feed mark at the bottom at the groove. In addition, lower spindle speed, $N$ and cutting speed, $v_{c}$ produced better surface roughness. According to Kiswanto et al. [9] feed rate, machining time and cutting length contribute significant effect on the surface roughness and burr formation. Longer machining time will effect on the tool condition and performance due to wear or delamination. Therefore, it drives resulting poor surface finish produce at cutting groove. 


\section{Conclusion}

In the present work, FEA was used to predict the laser beam-to-cutting tool distance, $X_{t-b}$ and depth of cut, $t_{c}$. Furthermore, the machining performance of Inconel 718 between conventional and LAMM condition was compared. The following conclusions can be drawn from this work:

i) The appropriate laser beam-to-cutting tool distance, $X_{t-b}$ when applied $P_{a v g} 4.16 \mathrm{~W}$, feed rate, $f_{r} 70 \mathrm{~mm} / \mathrm{min}$ and pulsed width, $t_{p} 1 \mathrm{~ms}$ is approximately to $250 \mu \mathrm{m}$. However, to avoid laser irradiate onto cutting tool due to beam diameter size of $700 \mu \mathrm{m}$, the distance was fix to $600 \mu \mathrm{m}$. Nevertheless, it able to improve surface quality.

ii) It is proven that LAMM technique with low pre-heating temperature significantly improves the surface roughness approximately $15 \%$ and reduces the undeformed chip thickness.

iii) Workpiece preheating method can be applied to reduce the ductility and yield strength of Inconel 718.

\section{Acknowledgements}

The author would like to acknowledge financial support from the Ministry of Education of Malaysia under the MyBrain15 program and Malaysian of Higher Education FRGS research grant (Vot 1425).

\section{References}

[1] S. Dharani and M. Pradip, "Finite element analysis of laser irradiated metal heating and melting processes,"Optics \& Laser Technology, Vol. 42, pp. 855-865, 2010.

[2] Z. Mohid, N. M. Warap, M. I. S. Ismail, R. Ibrahim and E. A. Rahim, "Determination of Heat Flux Intensity Distribution and Laser Absorption Rate of AISI D2 Tool Steel," Applied Mechanic and Materials, Vol. 465-466, pp. 730-734, 2014.

[3] X. D. Ren, Q. B. Zhan, S. Q. Yuan, J. Z. Zhou, Y. Wang, N. F. Ren, G. F. Sun, L. M. Zheng, F. Z. Zhai, H. M. Yang and W. J. Dai, "A finite element analysis of thermal relaxation of residual stress in laser shock processing Ni-based alloy GH4169," Materials and Design, Vol. 54, pp. 708-711, 2014.

[4] Z. Mohid, N. M. Warap, S. Hassan, M. I. S. Ismail, R. Ibrahim and E. A. Rahim, "Numerical Analysis of Laser Heating for Laser Assisted Micro Milling Application," Applied Mechanics and Materials, Vol. 465-466, pp. 720-724, 2014.

[5] Y. Jihong, S. Shoujin, B. Milan and Y. Wenyi, "Experimental investigation and 3D finite element prediction of the heat affected zone during laser assisted machining of Ti6Al4V alloy," Journal of Materials Processing Technology, Vol. 210, pp. 2215-2222, 2010.

[6] K. Dong-Hyeon and L. Choon-Man, "A study of cutting force and preheating-temperature prediction for laser-assisted milling of Inconel 718 and AISI 1045 steel," International Journal of Heat and Mass Transfer, Vol. 71, pp. 254-274, 2014.

[7] E. A. Rahim, Z. Mohid, N. M. Warap, M. R. Ibrahim and M. I. S. Ibrahim, "A Prediction of Laser Sport-to-Cutting Tool Distance in Laser Assisted Micro Milling," In International Conference of Micro Manufacturing, Singapore, 2014.

[8] O. Takenori Uno and M. Takashi, "Influnces of tool inclination on brittle fracture in glass cutting with ball end mills," Journal of Materials Processing Pechnology, Vol. 202, pp. 61-69, 2008.

[9] G. Kiswantoa, D. L. Zariatina and T. Ko, "The effect of spindle speed, feed-rate and machining time to the surface roughness and burr formation of Aluminum Alloy 1100 in micro-milling operation," Journal of Manufacturing Processes , 2014. 